\title{
Performance Evaluation of the GlucoDr Plus Glucometer
}

\author{
Dae-Hyun Ko, M.D., Soo Lim, M.D., Ph.D., ' Sang Hoon Song, M.D., \\ Sung Hee Choi, M.D., Ph.D., ${ }^{2}$ Young Joo Park, M.D., Ph.D., ${ }^{2}$ Kyoung Un Park, M.D., Ph.D.,' \\ Hak Chul Jang, M.D., Ph.D., ${ }^{2}$ and Junghan Song, M.D., Ph.D.
}

\begin{abstract}
Background: Because strict glucose control is important for reducing the complications of diabetes, the selfmonitoring of blood glucose is one of the fundamental treatment modalities. Many glucometers have been developed. In the present study, we evaluated a new glucometer: GlucoDr ${ }^{\mathrm{TM}}$ Plus (Allmedicus, Anyang, Gyeonggi-do, Republic of Korea).

Methods: The evaluation was performed based on Clinical and Laboratory Standards Institute guidelines. Interferences by ascorbic acid, uric acid, maltose, and acetaminophen were examined, and the performance of the unit was compared to those of six other glucometers. The effects of hematocrit, of oxygen partial pressure $\left(\mathrm{PaO}_{2}\right)$, and of multiple users were also evaluated.

Results: Within-run, between-run, between-day, and total imprecision (coefficients of variation) were 0.99$4.98 \%$. Satisfactory linearity was found for glucose concentrations of $32.5-786.5 \mathrm{mg} / \mathrm{dL}\left(R^{2}=0.9985\right)$. A comparison with the reference laboratory method showed close concordance over the entire range of concentrations evaluated $\left(R^{2}=0.9869\right)$. No significant effects were noted due to added interferents, hematocrit, and $\mathrm{PaO}_{2}$.

Conclusions: The GlucoDr Plus showed acceptable performance in terms of precision and linearity. It was minimally affected by various interferents. GlucoDr Plus is suitable for the self-monitoring of blood glucose by patients with diabetes.
\end{abstract}

\section{Introduction}

D IABETES MELLITUS is a metabolic disease that develops because of derangement of an individual's capacity to control blood glucose. In 2000, the number of patients with diabetes worldwide was estimated to be approximately 171 million, and this figure is expected to increase to 366 million in $2030 .{ }^{1}$ The discovery that strict blood glucose control is more helpful than relieving the symptoms of diabetes in terms of preventing complications represented a sentinel point in the treatment of diabetes. ${ }^{2,3}$ To achieve a good blood glucose control, patients should constantly check their blood glucose levels, and thus a portable glucometer is an essential device.

There are two types of glucometers, which rely on different signal detection principles, i.e., spectroscopic and electrochemical meters. When using spectroscopic meters, the amount of blood sample introduced to the response layer depends on the amount of blood loaded, which leads to measurement errors, and thus electrochemical meters are more widely used today. Methods of measuring blood glucose are classified according to the enzyme and coenzyme used, for example, the glucose oxidase method, the glucose dehydrogenase-based NAD method, the glucose dehydrogenase-based pyrroloqui- noline quinine method, the glucose dehydrogenase-based flavin adenine dinucleotide (FAD) method, the glucose hexokinase method, and others. Of these, the glucose oxidase method is most widely used. However, this method requires oxygen to convert glucose into gluconolactone, which can result in spuriously elevated values when oxygen contents are high in capillary or arterial blood. ${ }^{4}$ This problem can be overcome by using glucose dehydrogenase, which is not affected by oxygen content. However, the glucose dehydrogenasebased pyrroloquinoline quinine method is subject to interference by sugars other than glucose. ${ }^{5}$

In the present study, we evaluated the performance of a new glucometer, GlucoDr ${ }^{\mathrm{TM}}$ Plus (Allmedicus, Anyang, Gyeonggido, Republic of Korea), which utilizes a glucose dehydrogenasebased FAD method. We compared its performance with those of widely used glucometers.

\section{Materials and Methods}

\section{Glucometer}

The GlucoDr Plus is an electrochemical glucometer based on the glucose dehydrogenase method and displays blood glucose levels based on electric current generated by a

Departments of ${ }^{1}$ Laboratory Medicine and ${ }^{2}$ Internal Medicine, Seoul National University College of Medicine and Seoul National University Bundang Hospital, Gyeonggi-do, Republic of Korea. 
reaction between an enzyme immobilized on an electrode and glucose in blood. The system uses FAD-glucose dehydrogenase, which minimizes the effects of oxygen as well as sugars other than glucose. Gold is used for electrodes because of its noble nature and its high conductivity.

\section{Precision}

Three control solutions and five venous EDTA-treated whole blood samples were used to evaluate precision. Control solutions were measured twice a day for 20 days, as recommended by the Clinical Laboratory Standards Institute (CLSI), and within-run, between-run, between-day, and total imprecisions were calculated. ${ }^{6}$ Within-run imprecision in patient samples was assessed using 12 consecutive measurements of venous whole blood samples at five different concentrations.

\section{Linearity}

Two venous whole blood samples with glucose concentrations of 32.5 and $786.5 \mathrm{mg} / \mathrm{dL}$ were used, as recommended by the CLSI. ${ }^{7}$ The two samples were mixed in volume ratios of $4: 0,3: 1,2: 2,1: 3$, and $0: 4$ to produce five samples with different concentrations. Each sample was measured four times.

\section{Effect of hematocrit}

Twenty-one whole venous blood EDTA samples with hematocrit values of $12.1-58.0 \%$ were selected and measured with GlucoDr Plus. For each sample, plasma glucose concentrations were measured using an automated chemistry analyzer (model 200FR, Toshiba, Tokyo, Japan), and hematocrit effects were evaluated by calculating the ratio of glucose values measured by the glucometer and the automated chemistry analyzer.

\section{Interference}

Two venous whole blood EDTA-treated samples with different glucose concentrations were selected and measured five times with GlucoDr Plus to determine glucose concentrations before adding interferents. Low and high concentrations of ascorbic acid (3.5 and $6 \mathrm{mg} / \mathrm{dL}$ ), acetaminophen ( 3 and $8 \mathrm{mg} / \mathrm{dL}$ ), uric acid (7 and $25 \mathrm{mg} / \mathrm{dL}$ ), and maltose (10 and $200 \mathrm{mg} / \mathrm{dL}$ ) were then mixed with samples, and glucose concentrations were measured. The glucose concentrations determined before and after adding the interferents were compared. ${ }^{8}$

\section{Comparison with other glucometers and the automated chemistry analyzer}

One hundred twenty venous whole blood EDTA-treated samples with glucose concentrations in the range 33$327 \mathrm{mg} / \mathrm{dL}$ were randomly selected and tested using GlucoDr Plus and six other glucometers: Accu-Chek ${ }^{\circledR}$ (Roche Korea, Seoul, Republic of Korea), OneTouch ${ }^{\circledR}$ Ultra $^{\circledR}$ (LifeScan Korea, Seoul), Optium ${ }^{\text {TM }}$ Xceed (Abbott Korea, Seoul), Mirae 3.3G (Infopia, Anyang), Gluchec (KMH, Anyang), and MWD Pen Sensor (MedWatchDoc Gmbh \& Co., Lüneburg, Germany). All tests were performed twice, and results were evaluated according to the CLSI guidelines. ${ }^{9}$

\section{Test strip stability}

Three control solutions were measured using GlucoDr Plus immediately and 1,3, and 7 days after opening the test strip container. All tests were performed three times, and average values were compared.

\section{Effect of multiple users}

Three inexperienced persons were trained to operate GlucoDr Plus just prior to testing. Each person measured three control samples independently.

\section{Effect of oxygen partial pressure $\left(\mathrm{PaO}_{2}\right)$}

One hundred arterial whole blood heparinized samples with $\mathrm{PaO}_{2}$ values of $51.6-189.4 \mathrm{~mm} \mathrm{Hg}$ were randomly selected. Each sample was measured twice using GlucoDr Plus. Their plasma glucose concentrations were also measured twice using an automated chemistry analyzer. The effect of $\mathrm{PaO}_{2}$ was evaluated by calculating the ratio of glucose values measured by the automated chemistry analyzer and the glucometer.

\section{Statistics}

All statistical analyses were performed using Excel 2003 (Microsoft Corp., Redmond, WA) and SPSS version 15.0 for Windows (SPSS Inc., Chicago, IL). A correlation equation and Pearson's correlation coefficient $\left(R^{2}\right)$ were obtained during the correlation analysis. Clarke error grid analysis was performed to evaluate the clinical performance of the glucometer. Values of $P<0.05$ were deemed significant.

\section{Results}

\section{Precision}

Coefficients of variation (CVs) of within-run, betweenruns, between-days, and total imprecisions using the control solutions were $1.5-2.2 \%, 1.7-3.9 \%, 1.0-2.3 \%$, and $2.6-5.0 \%$, respectively (Table 1 ). CVs of with-run imprecisions using venous whole blood samples for glucose concentrations ranged from $1.3 \%$ to $5.0 \%$ (Table 1). GlucoDr Plus showed an acceptable range of imprecision that nearly meets the requirements for glucose measurements. ${ }^{10,11}$

\section{Linearity}

GlucoDr Plus showed acceptable linearity in the range $32.5-786.5 \mathrm{mg} / \mathrm{dL}$ (Fig. 1). The coefficient of determination was 0.998 , and the slope and intercept were 1 and 0 , respectively.

\section{Effect of hematocrit}

To evaluate the effect of hematocrit, 21 samples with a hematocrit of $12.1-58.0 \%$ and glucose concentrations in the range $57.5-369.5 \mathrm{mg} / \mathrm{dL}$ were used. Most of the values measured by GlucoDr Plus were slightly lower than those from the Toshiba 200-FR with minor exceptions. Glucose values obtained using GlucoDr Plus were different by $-10.9 \mathrm{mg} / \mathrm{dL}$ and $-7.1 \%$ on average. However, as shown in Figure 2, glucose values measured with GlucoDr Plus were not significantly affected by hematocrit $\left(R^{2}=0.0437, P=0.965\right)$. 
Table 1. Imprecision of GlucoDr Plus

\begin{tabular}{lccccc}
\hline & \multicolumn{4}{c}{ At mean glucose concentration $(\mathrm{mg} / \mathrm{dL})$} & \\
\cline { 2 - 5 } & Level 1 (44.3) & Level 2 (128.1) & Level 3 (365.6) & & \\
\hline Control solutions & & & & & \\
Within-run imprecision (\%) & 1.5 & 2.0 & 2.2 & \\
Between-run imprecision (\%) & 1.7 & 3.9 & 3.2 & \\
Between-day imprecision (\%) & 1.0 & 2.3 & 1.0 & & \\
Within-device imprecision (\%) & 2.6 & 5.0 & 4.1 & & \\
\hline & Level 1 (33.4) & Level 2 (95.8) & Level 3 (136.4) & Level 4 (204.9) & Level 5 (289.4) \\
\hline Patient samples & & & & & \\
Within-run imprecision (\%) & 5.0 & 1.3 & 2.7 & 3.0 & 2.1 \\
\hline
\end{tabular}

Imprecision (\%) is defined as CV.

\section{Interference}

Table 2 shows changes in measured glucose values after adding low or high concentrations of ascorbic acid, uric acid, maltose, or acetaminophen. No significant interference was observed from the four interferents tested. A degree of positive interference was found for ascorbic acid, up to about $10 \%$ of the initial glucose concentration. Interferences caused by uric acid, maltose, and acetaminophen at the difference glucose concentration were negligible.

\section{Comparison with the automated chemistry analyzer}

Correlations between the automated chemistry analyzer and the GlucoDr Plus and the six glucometers are shown in Table 3. All seven glucometers showed acceptable correlations $\left(R^{2}=0.9643-0.993\right)$. In terms of Clarke error grid analysis, all values were distributed in zone A (Fig. 3).

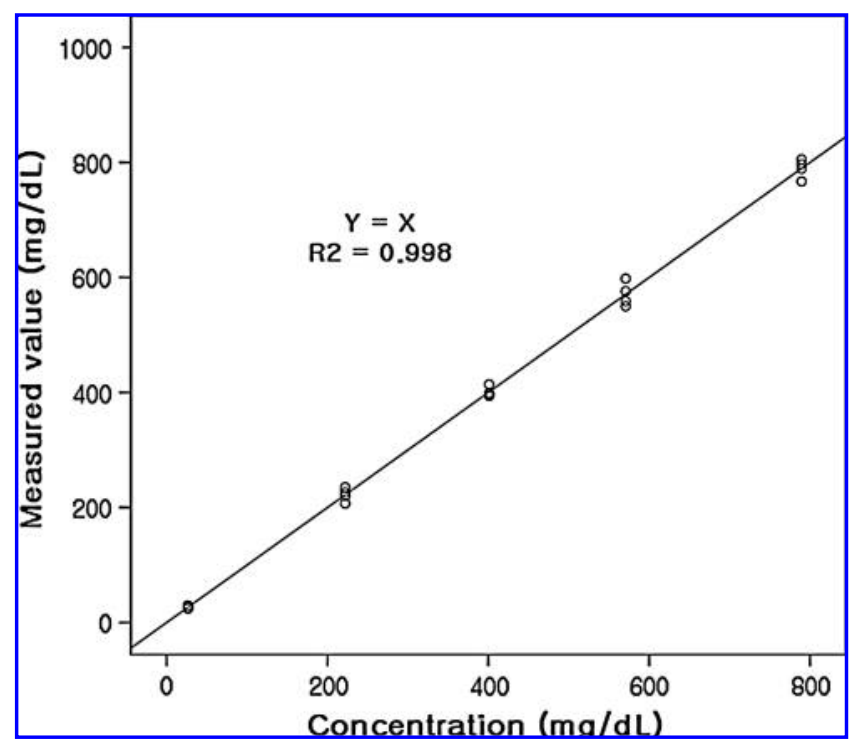

FIG. 1. Linearity of GlucoDr Plus measurements. The $x$-axis represents the expected value of glucose concentrations, and the $y$-axis represents measured values generated by the glucometer.

\section{Test strip stability}

Test strips were stable for 7 days after exposed to ambient environment. The average difference between glucose values after 7 days was within $\pm 3.4 \%$ of values obtained immediately after opening (Fig. 4). The differences at low and high concentrations were statistically significant $(P<0.01)$ but clinically insignificant (44.8-48.2 mg/dL at low concentration and $400.8-410.0 \mathrm{mg} / \mathrm{dL}$ at high concentration). The difference at the middle concentration was statistically and clinically insignificant $(P=0.271,127.6-132.2 \mathrm{mg} / \mathrm{dL})$.

\section{Effect of multiple users}

The CVs of glucose values measured by individual users were $4.7-6.3 \%, 1.7-2.9 \%$, and $2.5-2.8 \%$ for low, middle, and high concentration control solutions. Average values measured by the three users differed significantly at low concentration

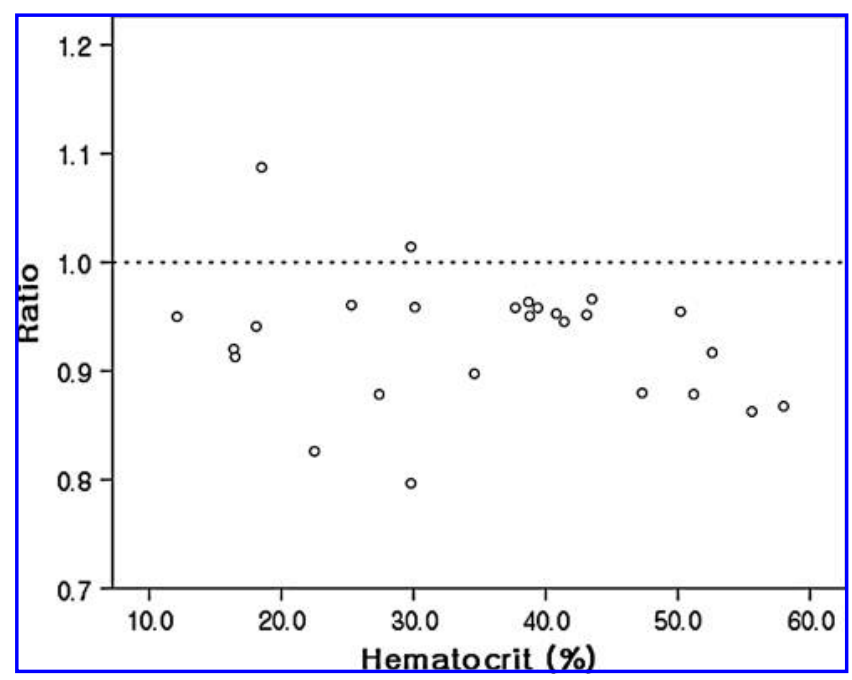

FIG. 2. Effect of hematocrit. The ratio was calculated as the glucose level resulted from the GlucoDr Plus divided by the glucose level measured by the Toshiba 200-FR analyzer. The dotted line indicates a reference line, i.e., a ratio of 1 . No significant correlation was noted between the hematocrit and the ratio calculated. 
TABle 2. INTERfEREnCE by AsCorbic ACID, URIC ACID, Maltose, AND ACETAMinOpHen

\begin{tabular}{lrrr}
\hline $\begin{array}{l}\text { Interferent } \\
\text { concentration } \\
(m g / d L)^{\mathrm{a}}\end{array}$ & $\begin{array}{c}\text { Glucose } \\
\text { concentration } \\
(m g / d L)^{\mathrm{b}}\end{array}$ & $m g / d L$ & $\%$ \\
\cline { 3 - 4 } & & & \\
Ascorbic acid & 80.6 & +0.4 & +0.5 \\
3.5 & 134.6 & +13.6 & +10.1 \\
3.5 & 71.4 & +3.6 & +5.0 \\
6 & 118.2 & +1.6 & +1.4 \\
6 & & & \\
Uric acid & 80.6 & -5.0 & -6.2 \\
7 & 134.6 & +7.2 & +5.3 \\
7 & 80.6 & -1.0 & -1.2 \\
25 & 134.6 & +8.2 & +6.1 \\
25 & & & \\
Maltose & 80.6 & -8.0 & -9.9 \\
10 & 134.6 & -1.4 & -1.0 \\
10 & 71.4 & +1.4 & +2.0 \\
200 & 118.2 & -5.8 & -4.9 \\
200 & & & \\
Acetaminophen & 80.6 & -1.8 & -2.2 \\
3 & 134.6 & -4.0 & -3.0 \\
3 & 71.4 & +1.6 & +2.2 \\
8 & 118.2 & +0.2 & +0.2 \\
8 & &
\end{tabular}

${ }^{\mathrm{a}}$ The concentrations of each interferent material added.

${ }^{b}$ Glucose concentration of sample to which each interferent material was mixed.

${ }^{\mathrm{c}}$ The difference of glucose concentration measured after addition of interferent substances. This was calculated by subtracting the measured value after the addition from the value before the manipulation. Data are absolute glucose levels and the relative percentage compared to initial values. A negative value means that addition of interferent substances lowered the measured values.

( $P=0.03)$ but not at the middle $(P=0.066)$ or high concentrations $(P=0.599)$. One user generated slightly lower values compared to those from others with a small difference (up to $7.7 \mathrm{mg} / \mathrm{dL})$.

\section{Effect of $\mathrm{PaO}_{2}$}

Figure 5 shows the results of arterial blood samples with $\mathrm{PaO}_{2}$ values ranging from 51.6 to $189.4 \mathrm{~mm} \mathrm{Hg}$. Measured glucose values in arterial whole blood and plasma were not affected by $\mathrm{PaO}_{2}\left(R^{2}=0.0302, P=0.086\right)$.

\section{Discussion}

Most patients with diabetes depend on a glucometer for their blood glucose control. Glucometer readings are used to guide patients to adjust insulin dosages in type 1 diabetes, and many type 2 diabetes patients are also using a glucometer to monitor their blood glucose levels. ${ }^{12}$ Thus, the analytical performance of the glucometer is of considerable importance as severe inaccuracies, imprecisions, or interferences may lead to inadequate treatment and adverse reactions. There is no guideline that specifies the quality goals only for precision. Most guidelines recommend total analytical goals, such as 5\% from the American Diabetes Association ${ }^{13}$ or $10 \%$ from the Clinical Laboratory Improvement Amendment 88 goal. None of currently used glucometers meet the above criteria. In this study, GlucoDr Plus was found to have a precision that was similar to or better than that of the other commercially available glucometers tested. Precision using patient samples was also excellent, although the CV was a little higher at low concentrations, which was expected. The International Standard Organization also recognizes this and thus recommends that the imprecision results should be reported in terms of CVs at glucose concentrations $>75 \mathrm{mg} / \mathrm{dL}$ and that SDs should be reported at concentrations $<75 \mathrm{mg} / \mathrm{dL} .{ }^{11}$ In terms of linearity, GlucoDr Plus showed excellent linearity in the range of 32.5$786.5 \mathrm{mg} / \mathrm{dL}$. The majority of commonly used glucometers do not guarantee linearity at $>500$ or $600 \mathrm{mg} / \mathrm{dL}$ or $<40 \mathrm{mg} / \mathrm{dL} .{ }^{4,14}$ This wider linear range of GlucoDr Plus may give some additional use for patients with extremely low or high levels of glucose that require immediate medical attention. The instrument may also be useful for neonates, who frequently have exceptionally low glucose levels, ${ }^{15}$ and for those patients suffering from brittle diabetes with uncontrollable glucose levels. However, further validation with samples from patients with various clinical conditions, such as dehydration, hemoconcentration, acidosis, or hypoglycemia, is required. In terms of correlations with automated chemistry analyzer findings, the results of all glucometers were comparable.

Because the red blood cell has less water than plasma, the amount of water may change in whole blood depending on

Table 3. Correlations of GlucoDr Plus and Six Other Glucometers with the Toshiba 200-FR Automated Chemistry Analyzer

\begin{tabular}{lccccc}
\hline Glucometer & $\begin{array}{c}\text { Range } \\
(m g / d L)^{\mathrm{a}}\end{array}$ & Slope $(95 \% \text { CI })^{\mathrm{b}}$ & ${\text { Intercept }(95 \% \text { CI })^{\mathrm{b}}}$ & ${\text { Mean bias }(\mathrm{mg} / \mathrm{dL})^{\mathrm{c}}}^{\text {Correlation }_{\text {coefficient }}^{\mathrm{d}}}$ \\
\hline GlucoDr Plus & $29-309$ & $0.963(0.942-0.983)$ & $-5.772(-7.845$ to -3.700$)$ & $-9.1(-10.2$ to -8.1$)$ & 0.993 \\
Accu-Chek & $28-312$ & $0.924(0.910-0.938)$ & $-3.447(-4.895$ to -2.000$)$ & $-10.2(-11.2$ to -9.3$)$ & 0.996 \\
OneTouch Ultra & $30-309$ & $0.965(0.936-0.994)$ & $-5.660(-8.618$ to -2.703$)$ & $-8.8(-10.3$ to -7.3$)$ & 0.987 \\
Optium Xceed & $20-321$ & $1.042(1.019-1.066)$ & $-13.735(-16.172$ to -11.299$)$ & $-9.9(-11.2$ to -8.7$)$ & 0.992 \\
Mi-rae 3.3G & $17-330$ & $0.998(0.965-1.031)$ & $-17.649(-21.038$ to -14.260$)$ & $-17.8(-19.5$ to -16.2$)$ & 0.984 \\
Gluchec & $30-320$ & $0.867(0.836-0.897)$ & $9.198(6.085-12.312)$ & $-2.7(-4.7$ to -0.8$)$ & 0.964 \\
MWD Pen Sensor & $24-235$ & $0.988(0.964-1.013)$ & $-1.220(-2.978-0.538)$ & $-2.0(-2.8$ to -1.2$)$ & 0.991 \\
\hline
\end{tabular}

${ }^{a}$ Range of glucose levels measured using each glucometer.

${ }^{b}$ Slope and intercept of regression analysis between each glucometer and the Toshiba 200-FR. Ninety-five percent confidence intervals of each value are given in parentheses.

${ }^{c}$ Difference between the glucose levels on the glucometer and the Toshiba 200-FR. A negative value means that the glucometer generated lower values of glucose compared to those resulting from the Toshiba 200-FR. Ninety-five percent confidence intervals of each value are presented in parentheses.

dPearson's correlation coefficient between the glucose levels on the glucometer and the Toshiba 200-FR. 


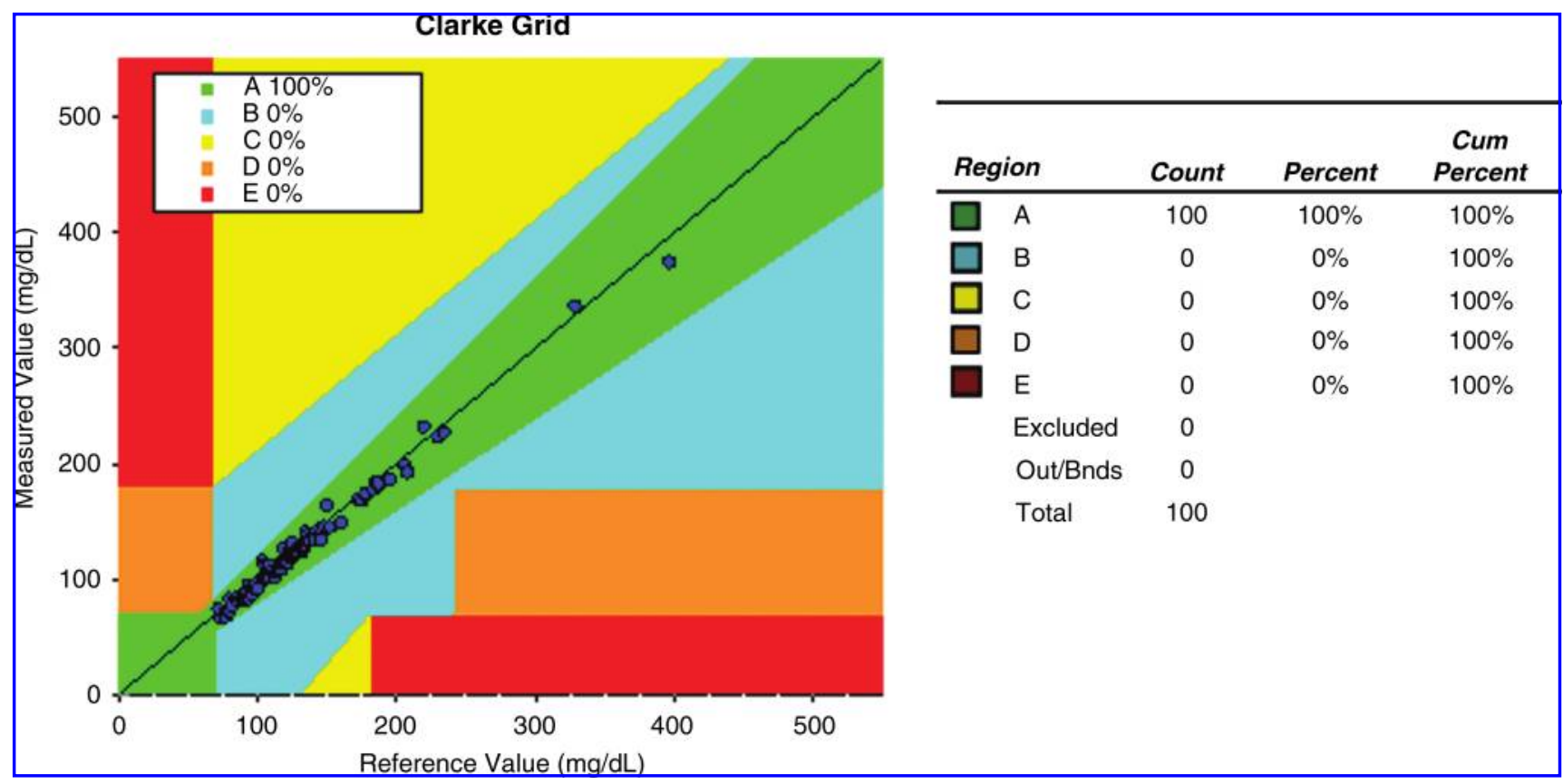

FIG. 3. Clarke error grid analysis of GlucoDr Plus measurements. The $x$-axis displays the glucose level recorded by the Toshiba 200-FR analyzer, and the glucose level generated from the GlucoDr Plus is displayed on the $y$-axis. All the measured valued are in zone A, i.e., acceptable error range.

the hematocrit. Therefore, it is known that blood glucose is measured lower than its true concentration because the amount of water becomes similar to that of plasma as the hematocrit gets higher. ${ }^{16}$ Compared to the automated chemistry analyzer, GlucoDr Plus appeared to produce slightly lower values as hematocrit levels increased, although this was not significant. The interference caused by various substances is one of the mostly easily overlooked problems associated with glucometer use. Ascorbic acid is the most well-known interferent, and high levels of ascorbic acid may cause positive

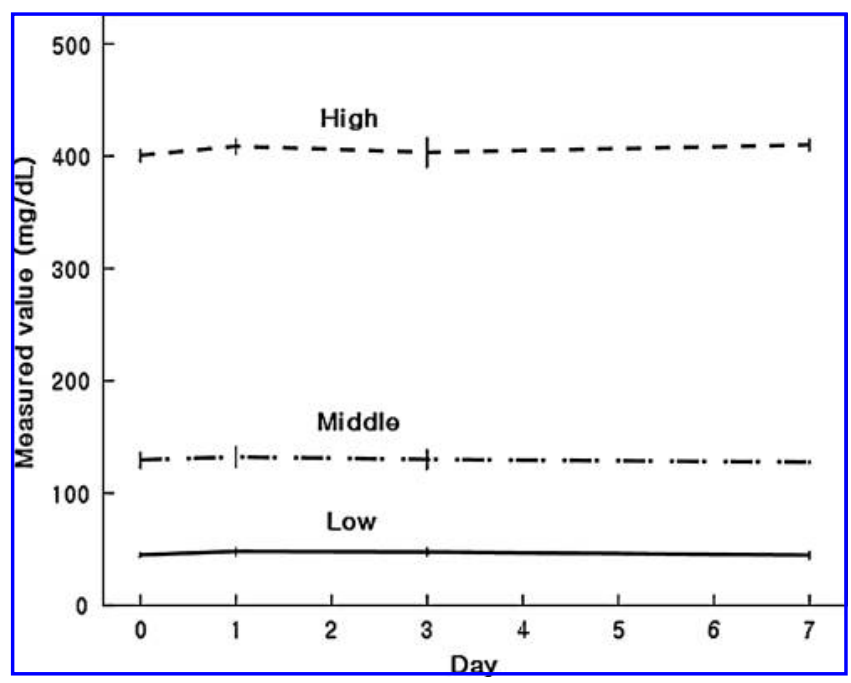

FIG. 4. Strip stability of GlucoDr Plus measurements. The day after opening is given on the $x$-axis. Measured values are glucose levels measured by the GlucoDr Plus expressed as means \pm 2 SEs. or negative divergences. ${ }^{13}$ In the present study, ascorbic acid, uric acid, maltose, and acetaminophen caused less than $11 \%$ differences in glucose levels. Higher level of interferents would have probably caused more severe interference, but higher levels were considered clinically unnecessary. GlucoDr Plus uses FAD extracted from Aspergillus oryzae as the cofactor, and it has been shown that the FAD-glucose dehydrogenase system is insensitive to oxygen and has high substrate specificity. ${ }^{17}$ Furthermore, $\mathrm{PaO}_{2}$ had no significant effects on

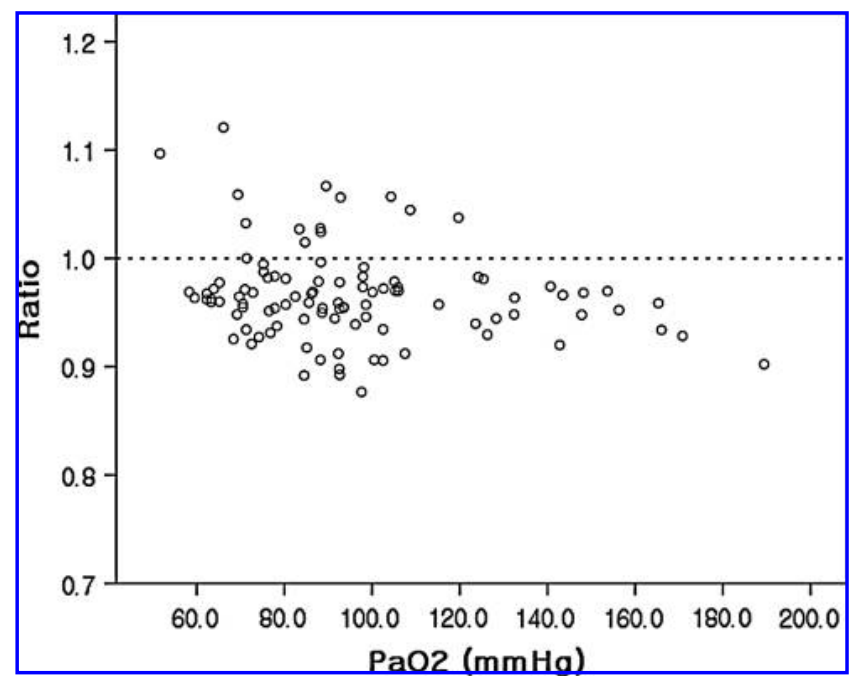

FIG. 5. Effect of $\mathrm{PaO}_{2}$. The ratio was calculated as the glucose level measured by the GlucoDr Plus divided by the glucose level measured by the Toshiba 200-FR analyzer. The dotted line indicates a reference line, i.e., a ratio of 1 . No significant correlation was noted between the $\mathrm{PaO}_{2}$ and the ratio calculated. 
GlucoDr Plus, and test strip stability was maintained for a week. The effects of longer test strip exposure periods and other environmental factors, such as temperature and humidity, should be determined by further study.

We evaluated the performance of GlucoDr Plus, a new FAD-glucose dehydrogenase-based electrochemical glucometer, using a standardized protocol. GlucoDr Plus matched or bettered the performances of other commonly used devices. We suggest that GlucoDr Plus is suitable for the selfmonitoring of blood glucose in patients with diabetes.

\section{Acknowledgments}

This study was supported by research grant from Allmedicus.

\section{Author Disclosure Statement}

No competing financial interests exist.

\section{References}

1. Wild S, Roglic G, Green A, Sicree R, King H: Global prevalence of diabetes: estimates for the year 2000 and projections for 2030. Diabetes Care 2004;27:1047-1053.

2. Turner C, Holman R, Cull A, Stratton M: Intensive bloodglucose control with sulphonylureas or insulin compared with conventional treatment and risk of complications in patients with type 2 diabetes (UKPDS 33). Lancet 1998;352: 837-853.

3. The effect of intensive treatment of diabetes on the development and progression of long-term complications in insulin-dependent diabetes mellitus. The Diabetes Control and Complications Trial Research Group. N Engl J Med 1993;329:977-986.

4. Tang Z, Louie RF, Lee JH, Lee DM, Miller EE, Kost GJ: Oxygen effects on glucose meter measurements with glucose dehydrogenase- and oxidase-based test strips for point-ofcare testing. Crit Care Med 2001;29:1062-1070.

5. Schleis TG: Interference of maltose, icodextrin, galactose, or xylose with some blood glucose monitoring systems. Pharmacotherapy 2007;27:1313-1321.

6. Clinical and Laboratory Standards Institute: Evaluation of Precision Performance of Quantitative Measurement Methods; Approved Guideline. CLSI document EP5-A2. Wayne, PA: Clinical and Laboratory Standards Institute, 2004.

7. Clinical and Laboratory Standards Institute: Evaluation of the Linearity of Quantitative Measurement Procedures: A Statistical Approach; Approved Guideline. CLSI document EP6-A. Wayne, PA: Clinical and Laboratory Standards Institute, 2003.

8. Clinical and Laboratory Standards Institute: Interference Testing in Clinical Chemistry; Approved Guideline. CLSI document EP7-A. Wayne, PA: Clinical and Laboratory Standards Institute, 2002.

9. Clinical and Laboratory Standards Institute: Method Comparison and Bias Estimation Using Patient Samples; Approved Guideline. CLSI document EP9-A. Wayne, PA: CLSI, 1995.
10. Barret E, Cameron J, Fraser G, Penberthy A, Shand L: A clinical view of analytical goals in clinical biochemistry. J Clin Pathol 1979;32:893-896.

11. International Organization for Standardization: In Vitro Diagnostic Test Systems-Requirements for Blood-Glucose Monitoring Systems for Self-Testing in Managing Diabetes Mellitus. International Standard Report Number ISO 15197: 2003(E). Geneva: International Organization for Standardization, 2003.

12. The Diabetes Control and Complications Trial/Epidemiology of Diabetes Interventions and Complications (DCCT/EDIC) Study Research Group: Intensive diabetes treatment and cardiovascular disease in patients with type 1 diabetes. $\underline{N}$ Engl J Med 2005;353:2643-2653.

13. Self-monitoring of blood glucose. American Diabetes Association. Diabetes Care 1994;17:81-86.

14. Tang Z, Du X, Louie RF, Kost GJ: Effects of drugs on glucose measurements with handheld glucose meters and a portable glucose analyzer. Am J Clin Pathol 2000;113:75-86.

15. American Academy of Pediatrics Committee on Fetus and Newborn: Routine evaluation of blood pressure, hematocrit, and glucose in newborns. Pediatrics 1993;92:474-476.

16. D'Orazio P, Burnett RW, Fogh-Andersen N, Jacobs E, Kuwa K, Külpmann WR, Larsson L, Lewenstam A, Maas AH, Mager G, Naskalski JW, Okorodudu AO; IFCC-SD-WGSEPOCT: Approved IFCC recommendation on reporting results for blood glucose: International Federation of Clinical Chemistry and Laboratory Medicine Scientific Division, Working Group on Selective Electrodes and Point-of-Care Testing (IFCC-SD-WG-SEPOCT). Clin Chem Lab Med 2006; 44:1486-1490.

17. Tsujimura S, Kojima S, Kano K, Ikeda T, Sato M, Sanada H, Omura H: Novel FAD-dependent glucose dehydrogenase for a dioxygen-insensitive glucose biosensor. Biosci Biotechnol Biochem 2006;70:654-659.

Address correspondence to:

Junghan Song, M.D., Ph.D.

Department of Laboratory Medicine Seoul National University Bundang Hospital 300 Gumi-dong

Bundang-gu, Seongnam-si, Gyeonggi-do 463-707, Republic of Korea

E-mail: songjhcp@snu.ac.kr

or

Hak Chul Jang, M.D., Ph.D. Department of Internal Medicine Seoul National University Bundang Hospital 300 Gumi-dong

Bundang-gu, Seongnam-si, Gyeonggi-do 463-707, Republic of Korea

E-mail: janghak@snu.ac.kr 
This article has been cited by:

1. 2010. Current literature in diabetes. Diabetes/Metabolism Research and Reviews 26:6, i-X. [CrossRef] 